\title{
Association between gestational diabetes mellitus and depression in parents: a retrospective cohort study
}

This article was published in the following Dove Press journal:

Clinical Epidemiology

\section{Romina Pace' \\ Elham Rahme ${ }^{1,2}$ \\ Deborah Da Costa ${ }^{1,2}$ \\ Kaberi Dasgupta ${ }^{1,2}$}

'Centre for Outcomes Research and Evaluation, Research Institute of the McGill University Health Centre, Montreal, QC, Canada; ${ }^{2}$ Department of Medicine, McGill University Health Center, Montreal, QC, Canada
Correspondence: Kaberi Dasgupta Centre for Outcomes Research and Evaluation, Research Institute of the McGill University Health Centre, 5252 boul de Maisonneuve, Office 3E.09, Montréal, QC H4A 3S5, Canada Tel + I 514934 I934 ext 447I5 Fax +I 5149348293

Email kaberi.dasgupta@mcgill.ca
Purpose: The aim of this study was to examine the association between gestational diabetes mellitus (GDM) and depression incidence in mothers and fathers during prenatal and postnatal periods.

Patients and methods: Matched pairs (GDM vs no GDM) of randomly selected mothers with singleton live births (matched by age group, delivery year, and health region) and their partners (Quebec, Canada; cohort inception 1990-2007) were assessed for a composite outcome of depression/self-harm/suicide using a health administrative database. We examined the association of GDM and the composite outcome in the following three nonoverlapping periods: 1) 24 weeks gestation up to delivery; 2) delivery up to 1 year postpartum; and 3) 1 year postpartum to study end (March 31, 2012). We used stratified Cox proportional regression hazards models, with three models in mothers and three models in fathers, corresponding to each of the time periods of interest.

Results: In the 58,400 mothers, women with GDM had a nearly twofold greater risk (adjusted HR: $1.82,95 \%$ CI 1.28, 2.59) of being diagnosed with depression compared to those without GDM during the prenatal period. In the first year postpartum, there was no conclusive difference observed between the two groups of mothers (adjusted HR: 1.05, 95\% CI 0.84, 1.30). Beyond the first year postpartum, there was an $8 \%$ increased risk (adjusted HR: $1.08,95 \%$ CI $1.03,1.14$ ) of depression in women with a history GDM compared to those without. A total of 63,384 fathers were included in our analyses, and no association between GDM in one's partner and depression was found during any of the three time periods evaluated.

Conclusion: GDM is associated with an increased risk of depression in women particularly during pregnancy highlighting the need to screen for depression and provide supportive interventions during this period.

Keywords: depression, self-harm, suicide, administrative health data, pregnancy, postpartum

\section{Introduction}

Depression is a prevalent condition that contributes to personal suffering and frequently coexists with chronic conditions, such as type 2 diabetes (termed diabetes hereafter). The American Diabetes Association and Diabetes Canada recommend screening for depression in all patients with diabetes. ${ }^{1,2}$ Common biological and behavioral mechanisms may underlie both depression and diabetes. These mechanisms include increased inflammation, hyperactivity of the sympathetic nervous system and hypothalamic pituitary adrenal axis, low levels of physical activity, unhealthy dietary habits, obesity, lower socioeconomic status, and chronic stress. ${ }^{3,4}$ Several studies have confirmed an association between depression and diabetes ${ }^{5}$ and suggest that the relationship is 
bidirectional. ${ }^{6,7}$ In contrast, there is less evidence evaluating the relationship between gestational diabetes mellitus (GDM) and depression.

The physiological changes in pregnancy can unmask a predisposition for diabetes in women, manifesting as GDM. ${ }^{8}$ GDM and depression pose important health concerns in mothers facing the challenges of pregnancy and motherhood; the prevalence of GDM is $\sim 16 \%$ globally in pregnant women $^{9}$ and roughly $12 \%$ of mothers experience perinatal depression. ${ }^{10}$ The relationship between these conditions is currently unclear. ${ }^{11}$ Some studies have identified an association between GDM and perinatal depression, ${ }^{12-15}$ whereas others have not. ${ }^{16-18}$ Differences in population demographics, measures for depression, and follow-up intervals may explain these conflicting results. Additionally, the association between GDM and depression outside the perinatal period is uncertain.

Depression is a critical problem not only for mothers but also for many fathers. As mothers, fathers undergo adjustments during pregnancy and following the birth of their infants. ${ }^{19}$ We previously demonstrated that during their partner's third trimester of pregnancy, $\sim 13 \%$ of expectant fathers experience depressive symptoms. ${ }^{20} \mathrm{~A}$ systematic review determined that the prevalence of paternal depression between the first trimester and 1 year postpartum was $\sim 8 \%{ }^{21}$ Furthermore, fathers share health behaviors, including dietary habits and physical activity with their partners, which are associated with developing GDM in mothers. ${ }^{22-27}$ We have also determined that GDM in mothers is associated with a higher risk of incident diabetes in fathers. ${ }^{28,29}$ The relationship between GDM in mothers and depression in fathers has not been previously investigated.

In the present study, we aim to elucidate the association between GDM and incident depression in the prenatal and postnatal periods and investigate the relationship between GDM in mothers and incident paternal depression.

\section{Methods}

\section{Study design, data sources, and construction of cohorts}

We conducted a population-based retrospective cohort study in the province of Quebec, Canada. Health administrative databases are maintained by the Quebec government (Régie de l'assurance maladie du Quebec [RAMQ]) for the universal public health insurance plan. Databases include procedural and diagnostic codes for physician outpatient visits (ICD-9) and hospitalization discharge diagnoses (ICD-9 until April 2006 and ICD-10 since then). The RAMQ identi- fied women aged 20-44 years who, between April 1, 1990, and December 31, 2007, 1) had a singleton live birth and 2 ) had $\geq 2$ outpatient physician billing diagnoses for GDM (ICD-9: 6480 or 6488, ICD-10: O24.8) within 6 months of delivery and/or a postdelivery hospitalization discharge GDM diagnosis. ${ }^{29}$ Each mother with GDM was matched by age group, the year of delivery, and local health administrative territory with a mother who had a singleton delivery without GDM diagnostic codes. Corresponding fathers and offspring were identified. Mother-father-child triads were excluded if incomplete or if there was a prior cardiovascular disease-related or heart failure diagnostic or procedural code in either parent. Anonymized data were received from the RAMQ and Quebec Statistical Institute (QSI), including diagnostic codes for mothers and fathers from 3 years prior to delivery to March 31, 2012 (RAMQ), month and year of death (RAMQ), month and year of offspring birth (RAMQ), age group of mothers and fathers (RAMQ), sex of infant (QSI), gestational age and size of infant (QSI), countries of birth and primary language of mothers and fathers (QSI), Institut national de santé publique du Québec material deprivation index ${ }^{30}$ (an area-level indicator of material deprivation, RAMQ), and mother and father co-habitation status at delivery (QSI).

From the cohort received from the RAMQ, we excluded all triads with any diagnostic code for diabetes in the father during the 3 years prior to the index delivery date or in the mother for the same period, excluding the index pregnancy. We also removed those with missing information on gestational age of infant or size of infant at birth. As universal screening for GDM is performed at 24-28 weeks gestation, ${ }^{31}$ for our analyses of maternal depression, we excluded mothers who had a history of psychiatric illness (mood and psychotic disorders) in the 1 year prior to 24 weeks gestation. For the analyses in our cohort of fathers, we excluded fathers who had any history of psychiatric illness in the 1 year prior to 24 weeks gestation. When a mother or father was excluded, their corresponding "match" was also excluded.

We examined the association of GDM and depression in the three nonoverlapping periods: 1) 24 weeks gestation up to delivery; 2) delivery up to 1 year postpartum; and 3) 1 year postpartum to study end (March 31, 2012). Follow-up was from the start of each period to departure from Quebec, death, or end of the period of interest. We defined incident depression in our administrative data as a composite of diagnosed depression ( $\geq 2$ outpatient visit diagnoses for depression within a 2-year time frame or one hospitalization discharge diagnosis), ${ }^{32}$ or hospital admission for self-harm or suicide 
recorded as a cause of death (for ICD codes used, refer Table S1). ${ }^{33}$ Baseline and outcome variables were assembled using SAS/STAT ${ }^{\circ}$ Version 9.4 (SAS Institute Inc., Cary, NC, USA).

\section{Study participants' characteristics at baseline}

We characterized mothers and fathers by age group, cohabitation with partner at delivery, parity, gestational hypertension diagnosis during index delivery, preterm delivery, size for gestational age of infant at delivery, prior comorbid conditions, history of psychiatric illness $>1$ year prior to 24 weeks gestation of the index pregnancy, history of psychiatric illness in partner, ethnicity, and socioeconomic status. Infants delivered at $<37$ weeks gestation were categorized as preterm, and infants were classified as small (weight $<10$ th percentile), appropriate (weight 10th to 90th percentile), and large (weight $>90$ th percentile) for gestational age, based on Canadian references. ${ }^{34}$ For comorbid conditions, we reviewed and grouped all diagnostic codes for the 3-year period prior to delivery. As airway disease was the only condition identified in $>5 \%$ of the cohort prior to delivery, we accounted only for this specific comorbid condition in our models. We also included hospital admissions in the 3 years prior to the index delivery as a comorbidity indicator. We defined the reference ethnocultural group (European origin) as those born in North America, Europe, or Australia with a first language of European origin. The use of the term "parents" refers to the pregnant woman herself (ie, the mother) and her partner (ie, the father of her infant).

\section{Statistical analyses}

We examined baseline characteristics (numbers and proportions) of mothers and fathers, stratified by the presence or absence of GDM in the index pregnancy. We computed depression incidence rates and plotted Kaplan-Meier curves for women with GDM, women without GDM, men whose partner had GDM, and men whose partner did not have GDM over the three time periods investigated to illustrate the diagnosis of depression in our cohort over time. The risk of depression was assessed using stratified Cox proportional regression hazards models. Variables included in the models were age group (for paternal analyses only as this was matched in mothers), co-habitation with partner at the birth of offspring, parity, gestational hypertension, preterm delivery, size for gestational age of infant, prior comorbid conditions, history of psychiatric illness $>1$ year prior to 24 weeks gestation of index pregnancy, history of psychiatric illness in partner, ethnicity, and socioeconomic status. Analyses were conducted using R Version 3.2.5 (R Development Core Team, 2016).

\section{Sensitivity analyses}

In sensitivity analyses, we explored the impact of a more liberal definition of incident depression that included a single outpatient physician visit or hospital discharge diagnosis or hospital admission for self-harm or suicide recorded as a cause of death. ${ }^{35}$ In addition, we examined the impact of excluding mothers and fathers with any ICD code for psychiatric illness in the 3 years prior to 24 weeks gestation of the index pregnancy. Finally, we included an interaction term between GDM and prior psychiatric illness in our models.

\section{Results}

Among the 80,000 triads selected at the RAMQ, 76,470 triads were identified in the Birth Registry and 70,136 triads remained following further exclusions (prior diabetes in parents or matched parents missing gestational age of infant or matched infant). After excluding mothers with any psychiatric illness in the year prior to 24 weeks gestation and their matches, 58,400 mothers were retained for analysis (Figure 1). A total of 63,384 fathers were included in our analyses after excluding fathers with a history of depression in the year prior to 24 weeks gestation and their matches (Figure 1).

\section{GDM and depression in mothers Baseline characteristics}

A slightly lower proportion of mothers with GDM were not living with their partners at the time of delivery compared to mothers without GDM (6.59 vs $8.08 \%$ ). Whereas nearly half $(50.54 \%)$ of mothers with GDM had more than one prior pregnancy, only one-third (28.43\%) of mothers without GDM were multiparous (Table 1). Mothers with GDM were more likely to have pregnancies complicated by gestational hypertension, preterm delivery, and large for gestational age infants compared to women without GDM. A higher proportion of mothers with GDM had previously been hospitalized. The proportions of airway disease were similar between both groups. Additionally, the proportions of psychiatric illness prior to 1 year from 24 weeks gestation of the index pregnancy and psychiatric illness in partners were similar in both groups. Mothers with GDM lived in deprived neighborhoods more frequently $(44.17 \%$ vs $38.14 \%$ ). A lower proportion of mothers with GDM were from a European ethnocultural background (76.84\% vs $82.26 \%$ ).

\section{GDM as a risk indicator for depression in mothers}

Mothers with GDM had a higher incidence of depression across all time periods investigated (Figure 2 and Table 2). 


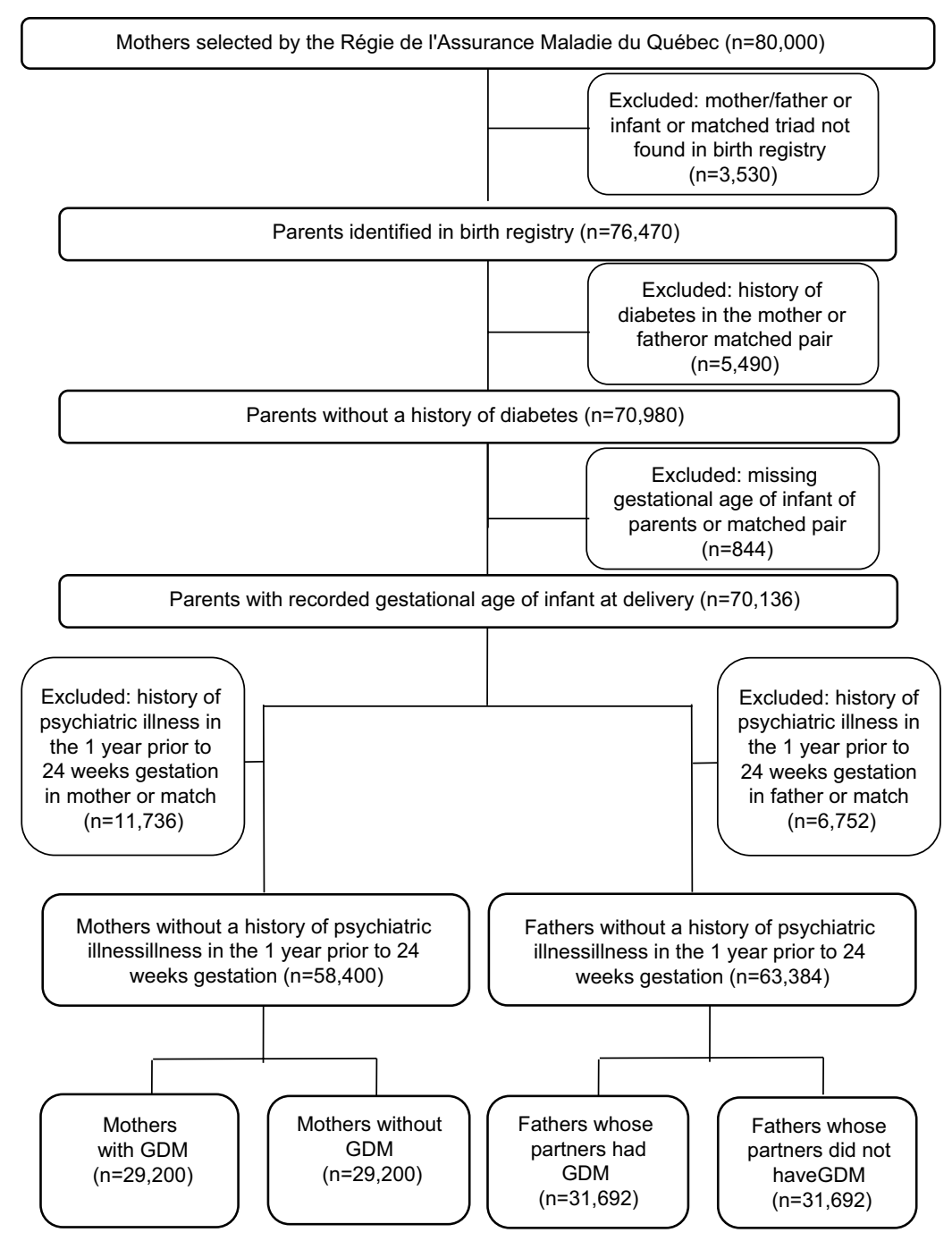

Figure I Participant flow diagram.

Abbreviation: GDM, gestational diabetes mellitus.

There were no recorded cases of self-harm or suicide in the first year postpartum. Over a mean follow-up of 11.95 years (SD: 5.59), 29 mothers with GDM and 25 mothers without GDM were admitted to hospital for self-harm and 12 mothers in each group had a cause of death reported as suicide. From the time of GDM diagnosis to delivery, a nearly twofold greater (adjusted HR: 1.82, 95\% CI 1.28, 2.59) risk of being diagnosed with depression was detected in mothers who had GDM compared to mothers without such a history. From delivery to 1 year postpartum, adjusted stratified Cox proportional regression hazards models demonstrated that the risk of being diagnosed with depression was not conclusively different between the two groups (adjusted HR: 1.05, 95\% CI $0.84,1.30$ ). Following the first year postpartum, there was an $8 \%$ (adjusted HR: $1.08,95 \%$ CI 1.03, 1.14) increased risk of depression/self-harm/suicide in women with a history GDM compared to those without.

\section{GDM and depression in fathers Baseline characteristics}

Fathers whose partners had GDM were slightly older than fathers whose partners did not have GDM (Table 3). In fathers whose partners had GDM, there was a lower proportion who had pirimiparous partners and were not living with their partner at the time of delivery compared to fathers whose partners did not have GDM. There were also a lower proportion of fathers with small for gestational age infants and of European background in the group whose partners had GDM compared to those whose partners did not have GDM. The proportion of partners with gestational hypertension, preterm infants, large 
Table I Maternal characteristics at baseline by GDM status (Quebec, Canada; 1990-2007)

\begin{tabular}{|c|c|c|c|c|}
\hline & \multicolumn{2}{|c|}{$\begin{array}{l}\text { Mothers without GDM } \\
(\mathrm{N}=\mathbf{2 9 , 2 0 0 )}\end{array}$} & \multicolumn{2}{|c|}{$\begin{array}{l}\text { Mothers with GDM } \\
(\mathrm{N}=\mathbf{2 9 , 2 0 0 )}\end{array}$} \\
\hline & $\mathbf{n}$ & $\%$ & $\mathbf{n}$ & $\%$ \\
\hline \multicolumn{5}{|l|}{ Age of mothers } \\
\hline$<30$ years & 13,309 & 45.78 & 13,309 & 45.58 \\
\hline $30-39$ years & 14,935 & 51.15 & 14,935 & 51.15 \\
\hline$\geq 40$ years & 956 & 3.27 & 956 & 3.27 \\
\hline Not living with partner at delivery & 2,359 & 8.08 & 1,924 & 6.59 \\
\hline \multicolumn{5}{|l|}{ Parity } \\
\hline One & 20,899 & 71.57 & 14,442 & 49.46 \\
\hline Two & 5,110 & 17.50 & 9,079 & 31.09 \\
\hline Three & 2,212 & 7.58 & 3,748 & 12.84 \\
\hline Greater than three & 979 & 3.35 & 1,931 & 6.61 \\
\hline Gestational hypertension & 2,173 & 7.44 & 3,694 & 12.65 \\
\hline Preterm delivery & $\mathrm{I}, 745$ & 5.98 & $2,46 I$ & 8.43 \\
\hline \multicolumn{5}{|l|}{ Infants' size at delivery ${ }^{\mathrm{a}}$} \\
\hline Small for gestational age ( $<10$ th percentile) & 3,199 & 10.96 & 2,538 & 8.69 \\
\hline Appropriate for gestational age (I0th to 90th percentile) & 23,855 & 81.70 & 22,927 & 78.52 \\
\hline Large for gestational age ( $>90$ th percentile) & 2,146 & 7.35 & 3,735 & 12.79 \\
\hline \multicolumn{5}{|l|}{ Comorbidity indicators } \\
\hline Hospitalization in prior to 3 years & 5,685 & 19.47 & 9,858 & 33.76 \\
\hline \multicolumn{5}{|l|}{ Diagnoses in $5 \%$ or more } \\
\hline Airway disease & 3,115 & 10.67 & 3,768 & 12.90 \\
\hline Psychiatric disorders & 2,926 & 10.02 & 3,140 & 10.75 \\
\hline History of psychiatric illness in partner & 2,675 & 9.16 & 2,610 & 8.94 \\
\hline Two most-deprived quintiles of deprivation index ${ }^{b}$ & $\mathrm{II}, \mathrm{I} 37$ & 38.14 & 12,899 & 44.17 \\
\hline European ethnocultural background ${ }^{c}$ & 24,021 & 82.26 & 22,437 & 76.84 \\
\hline
\end{tabular}

Notes: aased on Canadian birth data. ${ }^{34}$ bBased on neighborhood-level indicator of material deprivation. 'Based on primary language and country of birth. The ethnocultural groups considered non-Caucasian including South Asian, Southeast Asian, East Asian, West Asian, Afrocarribean, Central/South American, and Aboriginal.

Abbreviation: GDM, gestational diabetes mellitus.

for gestational age infants, and higher material deprivation was greater in fathers whose partner had GDM. There were no important differences in comorbidity indicators, history of psychiatric illness prior to 1 year from 24 weeks gestation of the index pregnancy, and history of psychiatric illness in partners between the two groups of fathers.

\section{GDM as a risk indicator for depression in fathers}

Over a mean follow-up of 12.43 years (SD: 5.38), in fathers whose partners did not have GDM, there were 16 fathers who were admitted to hospital for self-harm and 62 suicides. In parallel, there were 20 fathers whose partners had GDM who were admitted for self-harm and 68 fathers who committed suicide, with one of these suicides occurring in the first year postpartum. Cox proportional regression hazards models demonstrated no association with partner GDM status and depression in fathers (Table 3 ). There were very few cases of depression/self-harm/suicide (total $n=28$ ) in the 24 weeks gestation up to delivery period in fathers making these risk estimates imprecise.

\section{Other factors associated with depression in parents}

In mothers, a history of psychiatric illness was the strongest predictor of depression during pregnancy (Table 4; adjusted HR: $10.22,95 \%$ CI 5.64, 18.52). It was also the strongest predictor in both mothers and fathers during the first year postpartum (mothers - adjusted HR: 2.66, 95\% CI 1.86, 3.81; fathers - adjusted HR: $5.83,95 \%$ CI $2.93,11.59$ ) and following the first year postpartum (mothers - adjusted HR: 1.77, $95 \%$ CI 1.60, 1.96; fathers - adjusted HR: $2.73,95 \%$ CI $2.28,3.27)$. History of psychiatric illness in one's partner was a risk factor for depression in mothers after the first postpartum year (adjusted HR: $1.21,95 \%$ CI 1.08, 1.36) and a risk factor for depression in fathers in the first year postpartum (adjusted HR: $1.75,95 \%$ CI 1.02, 3.01) and thereafter (adjusted HR: $1.32,95 \%$ CI 1.16, 1.47). During pregnancy and after the first year postpartum, mothers who had small for gestational age infants were also at increased risk of depression (during pregnancy - adjusted HR: 2.13, 95\% CI 1.12, 4.05; after 1 year postpartum - adjusted HR: 1.13, 95\% CI 1.01, 1.26). No relationship was observed between infant characteristics 

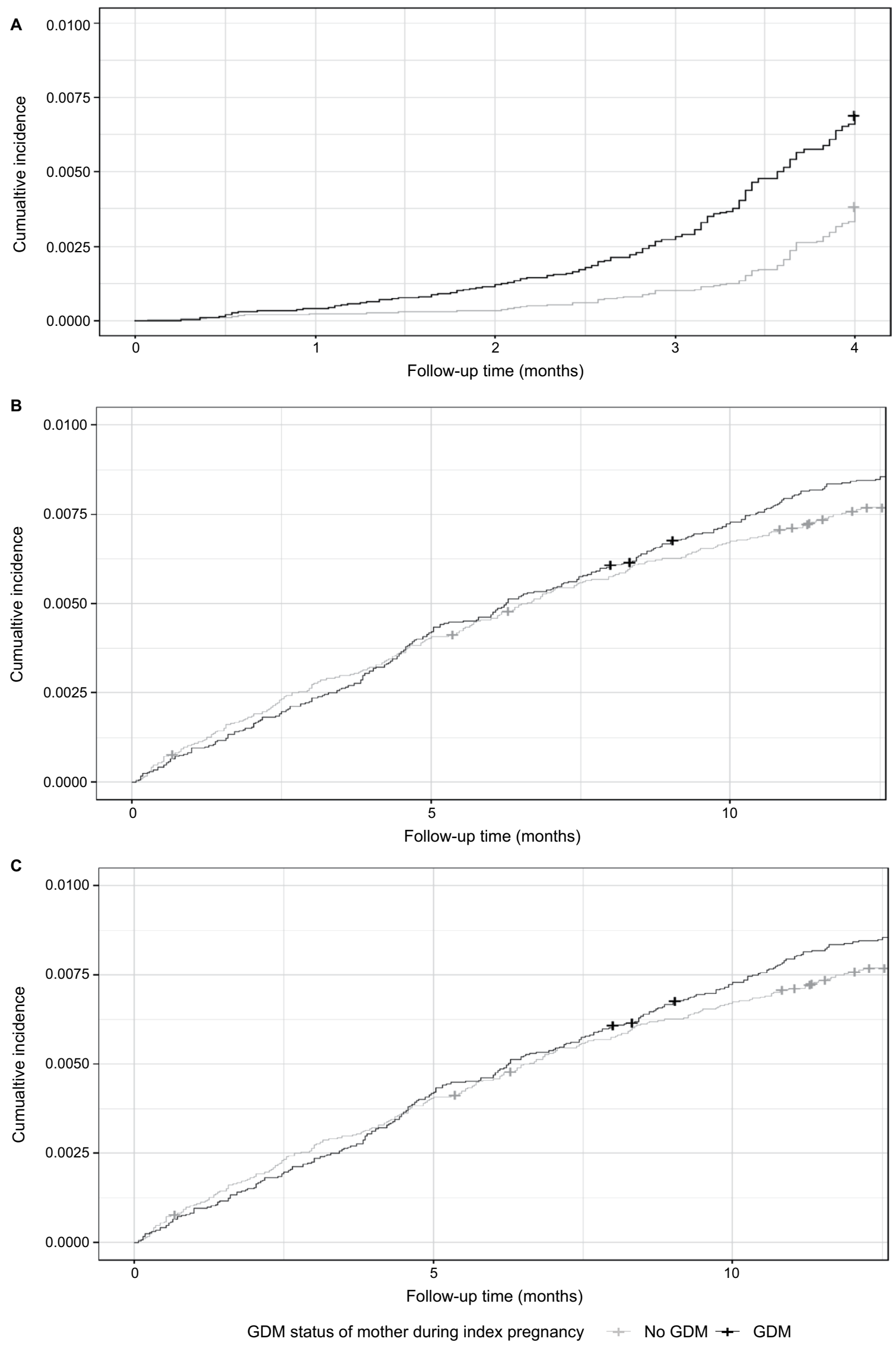

Figure 2 Kaplan-Meier curves of cumulative incidence of depression in mothers stratified by GDM status depression between (A) 24 weeks gestation to delivery; (B) delivery to I year postpartum; and (C) I year postpartum to the end of time period for which data were available (March 3I, 20I2). Abbreviation: GDM, gestational diabetes mellitus. 
Table 2 Depression case proportions, depression dates per I,000 person-years, and unadjusted and adjusted HRs computed through stratified Cox proportional regression hazards models in mothers and fathers in relationship with GDM status of index pregnancy (Quebec, Canada; 1990-2007)

\begin{tabular}{|c|c|c|c|c|c|c|}
\hline & \multicolumn{2}{|c|}{$\begin{array}{l}24 \text { weeks gestation to } \\
\text { delivery }\end{array}$} & \multicolumn{2}{|c|}{$\begin{array}{l}\text { Delivery to I year } \\
\text { postpartum }\end{array}$} & \multicolumn{2}{|c|}{$\begin{array}{l}\text { I year postpartum } \\
\text { to study end }\end{array}$} \\
\hline & $\begin{array}{l}\text { Non-GDM } \\
\text { pregnancy }\end{array}$ & $\begin{array}{l}\text { GDM } \\
\text { pregnancy }\end{array}$ & $\begin{array}{l}\text { Non-GDM } \\
\text { pregnancy }\end{array}$ & $\begin{array}{l}\text { GDM } \\
\text { pregnancy }\end{array}$ & $\begin{array}{l}\text { Non-GDM } \\
\text { pregnancy }\end{array}$ & $\begin{array}{l}\text { GDM } \\
\text { pregnancy }\end{array}$ \\
\hline \multicolumn{7}{|l|}{ Mothers } \\
\hline $\begin{array}{l}\text { Proportion diagnosed } \\
\text { with depression (n) }\end{array}$ & $\begin{array}{l}0.38 \% \\
(I I 2)\end{array}$ & $\begin{array}{l}0.69 \% \\
(202)\end{array}$ & $\begin{array}{l}0.77 \% \\
(226)\end{array}$ & $\begin{array}{l}0.86 \% \\
(250)\end{array}$ & $\begin{array}{l}14.28 \% \\
(4,17 \mid)\end{array}$ & $\begin{array}{l}15.48 \% \\
(4,52 I)\end{array}$ \\
\hline $\begin{array}{l}\text { Depression cases/I,000 } \\
\text { person-years }(95 \% \mathrm{Cl})\end{array}$ & $\begin{array}{l}12.52 \\
(10.41,14.94)\end{array}$ & $\begin{array}{l}22.60 \\
(19.70,25.82)\end{array}$ & $\begin{array}{l}6.04 \\
(5.30,6.85)\end{array}$ & $\begin{array}{l}6.73 \\
(5.95,7.59)\end{array}$ & \begin{tabular}{|l|}
12.35 \\
$(11.99,13.10)$
\end{tabular} & $\begin{array}{l}13.49 \\
(13.10,13.89)\end{array}$ \\
\hline Unadjusted HR (95\% Cl) & $\begin{array}{l}\text { I } \\
\text { (reference) }\end{array}$ & $\begin{array}{l}1.81 \\
(1.44,2.28)\end{array}$ & $\begin{array}{l}\text { I } \\
\text { (reference) }\end{array}$ & $\begin{array}{l}1.10 \\
(0.92,1.32) \\
\end{array}$ & $\begin{array}{l}\mathrm{I} \\
\text { (reference) }\end{array}$ & $\begin{array}{l}1.08 \\
(1.03,1.13) \\
\end{array}$ \\
\hline Adjusted HR ${ }^{\mathrm{a}}(95 \% \mathrm{Cl})$ & $\begin{array}{l}\text { I } \\
\text { (reference) }\end{array}$ & $\begin{array}{l}1.82 \\
(1.28,2.59)\end{array}$ & $\begin{array}{l}\text { I } \\
\text { (reference) }\end{array}$ & $\begin{array}{l}1.05 \\
(0.85,1.30)\end{array}$ & $\begin{array}{l}\text { I } \\
\text { (reference) }\end{array}$ & $\begin{array}{l}1.07 \\
(1.02,1.13)\end{array}$ \\
\hline \multicolumn{7}{|l|}{ Fathers } \\
\hline Cases of depression (n) & $\begin{array}{l}0.05 \% \\
(15)\end{array}$ & $\begin{array}{l}0.04 \% \\
(13)\end{array}$ & $\begin{array}{l}0.37 \% \\
(117)\end{array}$ & $\begin{array}{l}0.35 \% \\
(113)\end{array}$ & $\begin{array}{l}7.90 \% \\
(2,504)\end{array}$ & $\begin{array}{l}8.08 \% \\
(2,561)\end{array}$ \\
\hline $\begin{array}{l}\text { Depression cases/I,000 } \\
\text { person-years }(95 \% \mathrm{Cl})\end{array}$ & $\begin{array}{l}1.54 \\
(0.94,2.42)\end{array}$ & $\begin{array}{l}1.34 \\
(0.79,2.16)\end{array}$ & $\begin{array}{l}2.87 \\
(2.49,3.42)\end{array}$ & $\begin{array}{l}2.80 \\
(2.33,3.33)\end{array}$ & $\begin{array}{l}6.74 \\
(6.48,7.0 \mathrm{I})\end{array}$ & $\begin{array}{l}6.90 \\
(6.64,7.17)\end{array}$ \\
\hline Unadjusted HR $(95 \% \mathrm{Cl})$ & I & $\begin{array}{l}0.87 \\
(0.4 I, I .82)\end{array}$ & (reference) & $\begin{array}{l}0.97 \\
(0.75,1.25)\end{array}$ & $\begin{array}{l}\text { I } \\
\text { (reference) }\end{array}$ & $\begin{array}{l}1.03 \\
(0.97,1.09)\end{array}$ \\
\hline Adjusted HR $\mathrm{HR}^{\mathrm{a}}(95 \% \mathrm{Cl})$ & I & \begin{tabular}{|l|}
0.33 \\
$(0$, INF $)$
\end{tabular} & (reference) & $\begin{array}{l}0.75 \\
(0.52,1.09)\end{array}$ & $\begin{array}{l}\text { I } \\
\text { (reference) }\end{array}$ & $\begin{array}{l}1.02 \\
(0.95,1.09)\end{array}$ \\
\hline
\end{tabular}

Note: adjusted for parity, gestational hypertension, preterm delivery, size of infants at birth, comorbid conditions, not living with partner at the time of delivery, history of psychiatric illness, history of psychiatric illness in partner, deprivation index level, and ethnocultural background.

Abbreviations: GDM, gestational diabetes mellitus; INF, infinity.

and paternal depression. In the period following the first postpartum year, a history of not cohabitating with a partner at the time of delivery increased a mother's risk of depression by $20 \%$ (adjusted HR: $1.21,95 \%$ CI 1.06, 1.37). In fathers, higher material deprivation level was associated with a $21 \%$ (adjusted HR: 1.21, 95\% CI 1.10,1.32) increase in depression following the first year postpartum.

\section{Sensitivity analyses}

When utilizing a more liberal administrative health database definition for depression (a single outpatient or hospital discharge diagnosis), there was a trend toward increase rates of depression diagnoses in mothers with GDM, but no significant association was seen in fully adjusted proportional hazards models (Table S2). As in the main analyses, there was no association between GDM in partners and depression in fathers using the more liberal definition of depression. Other associations were similar to those observed in the main analyses.

When mothers with any history of psychiatric illness were excluded from analyses, the direction and magnitude of the association of GDM with depression from 1) 24 weeks gestation up to delivery (adjusted HR: 2.03, 95\%
CI $1.24,3.31)$,2) delivery up to the first year postpartum (adjusted HR: 1.12, 95\% CI 0.86, 1.46), and 3) 1 year postpartum to study end (adjusted HR: 1.07, 95\% CI 1.01, 1.13) were similar to our main analyses and remained conclusive. As in the main analyses, when fathers with any history of psychiatric illness were excluded, there was no association between GDM statuses of the partner with depression in fathers.

The addition of an interaction term between GDM and history of psychiatric illness was nonsignificant in all models examined.

\section{Discussion}

From the time of GDM screening to delivery, mothers with GDM had a nearly twofold higher risk of depression compared to mothers without GDM. Whereas GDM was not conclusively associated with depression during the 1-year postpartum period, later in life, there was a slightly higher risk of depression in women with a history of GDM compared to those without GDM. In contrast, no association between partner GDM status and paternal depression was observed. The American College of Obstetricians and Gynecologists recommends that all women is screened for depression at least 
Table 3 Paternal characteristics at baseline by GDM status of partner (Quebec, Canada; 1990-2007)

\begin{tabular}{|c|c|c|c|c|}
\hline & \multicolumn{2}{|c|}{$\begin{array}{l}\text { Partners without GDM } \\
(\mathrm{N}=31,692)\end{array}$} & \multicolumn{2}{|c|}{$\begin{array}{l}\text { Partners with GDM } \\
(\mathrm{N}=31,692)\end{array}$} \\
\hline & $\mathbf{n}$ & $\%$ & $\mathbf{n}$ & $\%$ \\
\hline \multicolumn{5}{|l|}{ Age of fathers } \\
\hline$<30$ years & 10,584 & 33.40 & 9,737 & 30.72 \\
\hline $30-39$ years & 17,377 & 54.83 & $|7,98|$ & 56.74 \\
\hline$\geq 40$ years & 3,731 & $1 \mathrm{I} .77$ & 3,974 & 12.54 \\
\hline Not living with partner at delivery & 2,643 & 8.34 & vv & 6.77 \\
\hline \multicolumn{5}{|l|}{ Partner's parity } \\
\hline One & 22,756 & 71.80 & 15,663 & 49.42 \\
\hline Two & 5,509 & 17.38 & 9,879 & 31.17 \\
\hline Three & 2,372 & 7.49 & 4,066 & 12.83 \\
\hline Greater than three & 1,055 & 3.33 & 2,084 & 6.58 \\
\hline Gestational hypertension in partner & 2,442 & 7.71 & 4,085 & 12.89 \\
\hline Preterm delivery & 1,900 & 6.00 & 2,702 & 8.53 \\
\hline \multicolumn{5}{|l|}{ Infants' size at delivery ${ }^{\mathrm{a}}$} \\
\hline Small for gestational age (<10th percentile) & 3,521 & $\mathrm{II} . \mathrm{II}$ & 2,740 & 8.65 \\
\hline Appropriate for gestational age (10th to 90th percentile) & 25,805 & 81.42 & 24,897 & 78.56 \\
\hline Large for gestational age (>90th percentile) & 2,366 & 7,47 & 4,055 & 12.80 \\
\hline \multicolumn{5}{|l|}{ Comorbidity indicators } \\
\hline Hospitalization in prior 3 years & 2,903 & 9.16 & 2,942 & 9.28 \\
\hline Airway disease & 2,405 & 7.59 & 2,751 & 8.68 \\
\hline History of psychiatric illness & $\mathrm{I}, 757$ & 5.54 & $\mathrm{I}, 763$ & 5.56 \\
\hline History of psychiatric illness in partner & 5,287 & 16.68 & 5,508 & 17.38 \\
\hline Two most-deprived quintiles of deprivation index & 11,838 & 37.35 & 13,732 & 43.33 \\
\hline European ethnocultural background ${ }^{c}$ & 25,992 & 82.01 & 24,363 & 76.87 \\
\hline
\end{tabular}

Notes: ${ }^{a}$ Based on Canadian birth data. ${ }^{34}$ based on neighborhood-level indicator of material deprivation. 'Based on primary language and country of birth. The ethnocultural groups considered non-Caucasian including South Asian, Southeast Asian, East Asian, West Asian, Afrocarribean, Central/South American, and Aboriginal.

Abbreviation: GDM, gestational diabetes mellitus.

once during pregnancy or in the postpartum period. ${ }^{36}$ This large retrospective cohort study demonstrates that screening is particularly important during pregnancy in mothers with GDM as they are at a much higher risk of depression during this period.

Our findings demonstrate an association between a diagnosis of GDM and a physician's diagnosis of depression during pregnancy, no association during the first year postpartum, and then a positive association beyond the first year postpartum. We suspect that the absence of an association during the first year postpartum may be related to the intensive child care duties during this period, perhaps limiting mothers' time available to consult a physician and thus be diagnosed with depression. A recent Canadian health administrative database study did not identify an association between GDM and depression either during pregnancy or during the first year postpartum $(\mathrm{N}=326,723$, including 12,140 with GDM).$^{18}$ We would note, however, that our study included approximately three times more women with GDM and was thus better powered to detect associations between GDM and depression. Two previous large health administrative database studies, one population-based Swedish study ( $\mathrm{N}=707,701$ deliveries, including 3,138 with GDM) and one focusing on a low-income sample in USA ( $\mathrm{N}=11,024$ deliveries, including 886 with GDM), specifically examined depression risk in the 1 -year postpartum period. ${ }^{14,15}$ Both reported an increased risk, in the order of a $70 \%$, in women with GDM vs those without GDM. In their main analyses, both retained women with prior depression but adjusted for this in their analyses. We excluded women with any psychiatric diagnosis in the 1-year period prior to 24 weeks gestation. These differences may partly account for the null association between depression and GDM that we observed in the first postpartum year. However, the association observed in the American study persisted with the exclusion of women with depression before delivery. ${ }^{14}$ Other population differences or health system differences may be operating, such as possibly a more systematic evaluation for depression postpartum in some jurisdictions or in low-income groups.

Smaller studies not relying on health administrative databases are able to systematically assess for depressed mood 
Table 4 Significant associations, as computed through stratified Cox proportional regression hazards models, of covariates with depression in mothers and fathers (Quebec, Canada; 1990-2007)

\begin{tabular}{|c|c|c|c|c|c|c|}
\hline & \multicolumn{2}{|c|}{$\begin{array}{l}24 \text { weeks gestation } \\
\text { to delivery }\end{array}$} & \multicolumn{2}{|c|}{$\begin{array}{l}\text { Delivery to I year } \\
\text { postpartum }\end{array}$} & \multicolumn{2}{|c|}{$\begin{array}{l}\text { I year postpartum to } \\
\text { study end }\end{array}$} \\
\hline & $\begin{array}{l}\text { Unadjusted, HR } \\
(95 \% \mathrm{Cl})\end{array}$ & $\begin{array}{l}\text { Adjusted, HR } \\
\text { (95\% Cl) }\end{array}$ & $\begin{array}{l}\text { Unadjusted, } \\
\text { HR ( } 95 \% \mathrm{Cl})\end{array}$ & $\begin{array}{l}\text { Adjusted, HR } \\
\text { (95\% Cl) }\end{array}$ & $\begin{array}{l}\text { Unadjusted, HR } \\
(95 \% \mathrm{Cl})\end{array}$ & $\begin{array}{l}\text { Adjusted, } \\
\operatorname{HR}(95 \% \mathrm{Cl})\end{array}$ \\
\hline \multicolumn{7}{|l|}{ Mothers } \\
\hline Preterm infant & $\begin{array}{l}1.64 \\
(1.00,2.70)\end{array}$ & $\begin{array}{l}1.80 \\
(0.93,3.46)\end{array}$ & $\begin{array}{l}1.26 \\
(0.79,2.02) \\
\end{array}$ & $\begin{array}{l}1.32 \\
(0.78,2.23) \\
\end{array}$ & $\begin{array}{l}0.93 \\
(0.82,1.06) \\
\end{array}$ & $\begin{array}{l}0.89 \\
(0.78,1.01)\end{array}$ \\
\hline Small for gestational age infant & $\begin{array}{l}1.80 \\
(1.12,2.89) \\
\end{array}$ & $\begin{array}{l}2.13 \\
(1.12,4.05) \\
\end{array}$ & $\begin{array}{l}1.39 \\
(0.90,2.15)\end{array}$ & $\begin{array}{l}1.53 \\
(0.96,2.45)\end{array}$ & $\begin{array}{l}1.13 \\
(1.01,1.27) \\
\end{array}$ & $\begin{array}{l}1.13 \\
(1.01,1.26)\end{array}$ \\
\hline Not living with partner & $\begin{array}{l}1.30 \\
(0.73,2.33)\end{array}$ & $\begin{array}{l}0.96 \\
(0.38,2.39) \\
\end{array}$ & $\begin{array}{l}1.21 \\
(0.70,2.08) \\
\end{array}$ & $\begin{array}{l}1.22 \\
(0.67,2.22) \\
\end{array}$ & $\begin{array}{l}1.23 \\
(1.08,1.39) \\
\end{array}$ & $\begin{array}{l}1.20 \\
(1.05,1.37)\end{array}$ \\
\hline History of psychiatric illness & $\begin{array}{l}10.00 \\
(5.88,17.00) \\
\end{array}$ & $\begin{array}{l}10.22 \\
(5.64,18.52)\end{array}$ & $\begin{array}{l}2.51 \\
(1.72,3.66) \\
\end{array}$ & $\begin{array}{l}2.66 \\
(1.86,3.81) \\
\end{array}$ & $\begin{array}{l}1.95 \\
(1.77,2.15) \\
\end{array}$ & $\begin{array}{l}1.77 \\
(1.60,1.96) \\
\end{array}$ \\
\hline $\begin{array}{l}\text { History of psychiatric illness in } \\
\text { partner }\end{array}$ & $\begin{array}{l}1.50 \\
(0.91,2.46)\end{array}$ & $\begin{array}{l}1.12 \\
(0.56,2.22)\end{array}$ & $\begin{array}{l}1.16 \\
(0.79,1.70)\end{array}$ & $\begin{array}{l}1.18 \\
(0.77,1.81)\end{array}$ & $\begin{array}{l}1.30 \\
(1.16,1.46)\end{array}$ & $\begin{array}{l}1.21 \\
(1.08,1.36)\end{array}$ \\
\hline High deprivation index ${ }^{a}$ & $\begin{array}{l}1.00 \\
(0.94,1.08)\end{array}$ & $\begin{array}{l}1.02 \\
(0.95,1.10)\end{array}$ & $\begin{array}{l}1.04 \\
(0.78,1.39)\end{array}$ & $\begin{array}{l}1.09 \\
(0.79,1.49) \\
\end{array}$ & $\begin{array}{l}1.00 \\
(0.94,1.08) \\
\end{array}$ & $\begin{array}{l}1.02 \\
(0.95,1.10)\end{array}$ \\
\hline European origin & $\begin{array}{l}1.96 \\
(1.18,3.23)\end{array}$ & $\begin{array}{l}1.69 \\
(0.79,3.62) \\
\end{array}$ & $\begin{array}{l}1.56 \\
(0.99,2.48) \\
\end{array}$ & $\begin{array}{l}1.88 \\
(1.23,2.87)\end{array}$ & $\begin{array}{l}2.06 \\
(1.84,2.30) \\
\end{array}$ & $\begin{array}{l}1.89 \\
(1.76,2.23)\end{array}$ \\
\hline \multicolumn{7}{|l|}{ Fathers } \\
\hline Preterm infant & $\begin{array}{l}2.19 \times 10^{8} \\
(0, \mathrm{INF})\end{array}$ & $\begin{array}{l}15.43 \\
(0, \text { INF) }\end{array}$ & $\begin{array}{l}0.95 \\
(0.50,1.81)\end{array}$ & $\begin{array}{l}0.80 \\
(0.36, I .8 I)\end{array}$ & $\begin{array}{l}0.98 \\
(0.84,1.14)\end{array}$ & $\begin{array}{l}0.95 \\
(081,1.12)\end{array}$ \\
\hline Small for gestational age infant & $\begin{array}{l}0.25 \\
(0.02,2.74) \\
\end{array}$ & $\begin{array}{l}311.50 \\
(0, I N F) \\
\end{array}$ & $\begin{array}{l}0.68 \\
(0.38,1.20) \\
\end{array}$ & $\begin{array}{l}0.42 \\
(0.21,0.85) \\
\end{array}$ & $\begin{array}{l}1.09 \\
(0.96,1.25) \\
\end{array}$ & $\begin{array}{l}1.06 \\
(0.93,1.22) \\
\end{array}$ \\
\hline Not living with partner & $\begin{array}{l}1.00 \\
(0.14,7.10)\end{array}$ & $\begin{array}{l}0.01 \\
(0, \text { INF) }\end{array}$ & $\begin{array}{l}0.75 \\
(0.35,1.59) \\
\end{array}$ & $\begin{array}{l}0.76 \\
(0.30,1.93) \\
\end{array}$ & $\begin{array}{l}1.04 \\
(0.89,1.21) \\
\end{array}$ & $\begin{array}{l}1.01 \\
(0.86,1.20)\end{array}$ \\
\hline History of psychiatric illness & $\begin{array}{l}1.62 \times 10^{9} \\
(0, \text { INF })\end{array}$ & $\begin{array}{l}1.95 \times 10^{10} \\
(0, \text { INF })\end{array}$ & $\begin{array}{l}5.33 \\
(2.88,9.88) \\
\end{array}$ & $\begin{array}{l}5.83 \\
(2.93,11.59) \\
\end{array}$ & $\begin{array}{l}2.97 \\
(2.49,3.54) \\
\end{array}$ & $\begin{array}{l}2.73 \\
(2.28,3.27) \\
\end{array}$ \\
\hline $\begin{array}{l}\text { History of psychiatric illness in } \\
\text { partner }\end{array}$ & $\begin{array}{l}2.00 \\
(0.60,6.64) \\
\end{array}$ & $\begin{array}{l}0.01 \\
(0, I N F) \\
\end{array}$ & $\begin{array}{l}1.90 \\
(1.21,2.97)\end{array}$ & $\begin{array}{l}1.75 \\
(1.02,3.01) \\
\end{array}$ & $\begin{array}{l}1.42 \\
(1.28,1.57) \\
\end{array}$ & $\begin{array}{l}1.32 \\
(1.18,1.47)\end{array}$ \\
\hline High deprivation index ${ }^{a}$ & $\begin{array}{l}1.29 \\
(0.48,3.45) \\
\end{array}$ & $\begin{array}{l}0.021 \\
(0, I N F) \\
\end{array}$ & $\begin{array}{l}1.06 \\
(0.72,1.58) \\
\end{array}$ & $\begin{array}{l}1.22 \\
(0.75,2.00) \\
\end{array}$ & $\begin{array}{l}1.17 \\
(1.07,1.27) \\
\end{array}$ & $\begin{array}{l}1.21 \\
(1.11,1.33)\end{array}$ \\
\hline European origin & $\begin{array}{l}1.62 \times 10^{9} \\
(0, \text { INF })\end{array}$ & $\begin{array}{l}\mathrm{I} .44 \\
(0, \mathrm{INF})\end{array}$ & $\begin{array}{l}2.06 \\
(1.14,3.75)\end{array}$ & $\begin{array}{l}2.44 \\
(1.17,5.06)\end{array}$ & $\begin{array}{l}2.39 \\
(2.07,2.76)\end{array}$ & $\begin{array}{l}2.38 \\
(2.06,2.77)\end{array}$ \\
\hline
\end{tabular}

Note: ${ }^{a}$ Two most-deprived quintiles of deprivation index.

Abbreviation: INF, infinity.

using validated instruments. They are thus able to detect depressive symptomology that may not otherwise come to a health care provider's attention. We identified two such studies that detected no association, perhaps because of small sample size. ${ }^{37,38} \mathrm{~A}$ third study observed findings consistent with ours: Huang et al determined, using the Edinburgh Postnatal Depression Scale, that women with GDM had higher depression scores during mid-pregnancy than those without GDM but found no difference in scores at 6 months postpartum. ${ }^{39} \mathrm{~A}$ fourth study observed a strong association between depressive symptomology and GDM at 6 weeks postpartum. ${ }^{12}$ This is consistent with the possibility that in the first year postpartum, mothers may not seek medical attention for themselves. ${ }^{40,41}$ It should be noted that, because of the smaller sample size, the CI was wide in this study (RR 4.62, 95\% CI 1.26, 16.98), at the lower end suggestive of a small association and at the higher end suggestive of an implausibly strong association.

Years after pregnancy, GDM has been shown to have associations with incident diabetes, hypertension, and cardiovascular disease, ${ }^{29,42,43}$ but few studies have assessed the long-term relationship between GDM and depression. In this study, we were able to establish the forward directionality of the likely bidirectional relationship of GDM and depression; GDM signals maternal depression during and after pregnancy. Beyond the first postpartum year, over a median of 4 years, an association between GDM and incident depression was previously shown to be attenuated after adjustment for socioeconomic and clinical variables (adjusted OR 1.29, $95 \%$ CI $0.98,1.70) .{ }^{17}$ In comparison to this prior study, the present study had more women with GDM (29,200 vs 659) and a much longer follow-up time; over a mean follow-up 
of 11.95 years (SD: 5.59), there was an $8 \%$ higher risk for depression in mothers who had GDM in our study.

This is the first study to investigate a relationship between GDM in mothers and incident depression in fathers. We hypothesized that given shared dietary and behavioral habits between partners, which are associated with both GDM and depression, GDM in mothers may signal depression in fathers. However, we found no such association. This study does confirm that a previous personal history of depression having a partner with a history of depression is a risk factor for postpartum depression in both men and women. ${ }^{44-47}$ In the first 6 months postpartum, Paulson et $\mathrm{al}^{48}$ showed that mothers with prenatally depressed partners had significant worsening in depressive symptoms, but they observed no association between partner depression and paternal depression in fathers, in contrast to our findings. Other studies have found that elevated depressive symptomatology in one partner is significantly associated with corresponding increases in the other's symptoms. ${ }^{45,49}$ Depression in parents impacts a child's behavioral, emotional, cognitive, and physical development. ${ }^{50,51}$ Our findings highlight that depression in one partner has reciprocal effects on the other suggesting that interventions for depression in the postnatal period should have a family centered approach. ${ }^{52}$

We acknowledge some limitations. We did not have any data on physical activity, eating habits, smoking, or other health behaviors, or did we have information on body mass index. However, as shared behaviors are likely along the causal pathway, we would not have included them as variables in the main analyses examining the relationship between GDM and depression. Individuals of non-European ancestry born in North America, Europe, or Australia who reported a European first language were classified in the reference ethnocultural category and thus arguably misclassified. As with all administrative health data studies, our results are subject to detection bias as a diagnosis is only recorded if an individual has an encounter with the healthcare system and prior studies have shown that women are reluctant to seek care for mental health problems during the perinatal period. ${ }^{40,41}$ Moreover, using administrative data, we are unable to directly apply clinical definitions of depression such as those delineated by the Diagnostic and Statistical Manual of Mental Disorders (DSM-5) and the WHO. Strengths of our study included a cohort design, a large number of subjects and indicators of psychiatric illness in partner, cohabitation status, ethnocultural background, deprivation level, and variables not available in many health administrative database studies.

\section{Conclusion}

Women with GDM are at an increased risk of depression particularly during pregnancy underscoring the need to screen for depression in these mothers and provide supportive interventions. This study also emphasizes that prior psychiatric illness, and having a partner with a history of psychiatric illness impacts the risk of depression in both mothers and fathers highlighting the importance for healthcare providers to consider the mental health status of both parents.

\section{Acknowledgments}

We would like to thank the QSI and the RAMQ, and their teams, for working with us to ensure that data were appropriately selected, collated, and transmitted. We would like to thank Youssef Habel for merging the data sets we received. This study has been conducted with the support of Diabetes Canada.

\section{Disclosure}

The authors report no conflicts of interest in this work.

\section{References}

1. American Diabetes Association. 4. Lifestyle Management: Standards of Medical Care in Diabetes 2018. Diabetes Care. 2018;41(Suppl 1):S38-S50

2. Diabetes Canada Clinical Practice Guidelines Expert Committee, Robinson DJ, Coons M, Haensel H, Vallis M, Yale JF. Diabetes and Mental Health. Can J Diabetes. 2018;42 (Suppl 1):S130-S141.

3. Champaneri S, Wand GS, Malhotra SS, Casagrande SS, Golden SH. Biological basis of depression in adults with diabetes. Curr Diab Rep. 2010;10(6):396-405.

4. Holt RI, de Groot M, Golden SH. Diabetes and depression. Curr Diab Rep. 2014;14(6):491.

5. Anderson RJ, Freedland KE, Clouse RE, Lustman PJ. The prevalence of comorbid depression in adults with diabetes: a meta-analysis. Diabetes Care. 2001;24(6):1069-1078.

6. Golden SH, Lazo M, Carnethon M, et al. Examining a bidirectional association between depressive symptoms and diabetes. JAMA. 2008;299(23):2751-2759.

7. Pan A, Lucas M, Sun Q, et al. Bidirectional association between depression and type 2 diabetes mellitus in women. Arch Intern Med. 2010;170(21):1884-1891.

8. Bellamy L, Casas J-P, Hingorani AD, Williams DJ. Pre-eclampsia and risk of cardiovascular disease and cancer in later life: systematic review and meta-analysis. BMJ. 2007;335(7627):974.

9. Guariguata L, Linnenkamp U, Beagley J, Whiting DR, Cho NH. Global estimates of the prevalence of hyperglycaemia in pregnancy. Diabetes Res Clin Pract. 2014;103(2):176-185.

10. Woody CA, Ferrari AJ, Siskind DJ, Whiteford HA, Harris MG. A systematic review and meta-regression of the prevalence and incidence of perinatal depression. J Affect Disord. 2017;219:86-92.

11. Ross GP, Falhammar H, Chen R, Barraclough H, Kleivenes O, Gallen I. Relationship between depression and diabetes in pregnancy: a systematic review. World J Diabetes. 2016;7(19):554-571.

12. Hinkle SN, Buck Louis GM, Rawal S, Zhu Y, Albert PS, Zhang C. A longitudinal study of depression and gestational diabetes in pregnancy and the postpartum period. Diabetologia. 2016;59(12):2594-2602. 
13. Abdollahi F, Zarghami M, Azhar MZ, Sazlina SG, Lye MS. Predictors and incidence of post-partum depression: a longitudinal cohort study. J Obstet Gynaecol Res. 2014;40(12):2191-2200.

14. Kozhimannil KB, Pereira MA, Harlow BL. Association between diabetes and perinatal depression among low-income mothers. JAMA. 2009;301(8):842-847.

15. Silverman ME, Reichenberg A, Savitz DA, et al. The risk factors for postpartum depression: a population-based study. Depress Anxiety. 2017;34(2):178-187.

16. Miller ES, Peri MR, Gossett DR. The association between diabetes and postpartum depression. Arch Womens Ment Health. 2016;19(1):183-186.

17. Walmer R, Huynh J, Wenger J, et al. Mental health disorders subsequent to gestational diabetes mellitus differ by race/ethnicity. Depress Anxiety. 2015;32(10):774-782.

18. Beka Q, Bowker S, Savu A, Kingston D, Johnson JA, Kaul P. Development of perinatal mental illness in women with gestational diabetes mellitus: a population-based cohort study. Can J Diabetes. 2018;42(4):350-355.

19. Goodman JH. Paternal postpartum depression, its relationship to maternal postpartum depression, and implications for family health. $J$ Adv Nurs. 2004;45(1):26-35.

20. da Costa D, Zelkowitz P, Dasgupta K, et al. Dads get sad too: depressive symptoms and associated factors in expectant first-time fathers. Am J Mens Health. 2017;11(5):1376-1384.

21. Cameron EE, Sedov ID, Tomfohr-Madsen LM. Prevalence of paternal depression in pregnancy and the postpartum: an updated meta-analysis. J Affect Disord. 2016;206:189-203.

22. Pachucki MA, Jacques PF, Christakis NA. Social network concordance in food choice among spouses, friends, and siblings. Am J Public Health. 2011;101(11):2170-2177.

23. Macario E, Sorensen G. Spousal similarities in fruit and vegetable consumption. Am J Health Promot. 1998;12(6):369-377.

24. Barrett-Connor E, Suarez L, Criqui MH. Spouse concordance of plasma cholesterol and triglyceride. J Chronic Dis. 1982;35(5):333-340.

25. Cobb LK, Godino JG, Selvin E, Kucharska-Newton A, Coresh J, Koton S. Spousal influence on physical activity in middle-aged and older adults: the ARIC study. Am J Epidemiol. 2016;183(5):444-451.

26. Falba TA, Sindelar JL. Spousal concordance in health behavior change. Health Serv Res. 2008;43(1 Pt 1):96-116.

27. Jackson SE, Steptoe A, Wardle J. The influence of partner's behavior on health behavior change: the English Longitudinal Study of Ageing. JAMA Intern Med. 2015;175(3):385-392.

28. Dasgupta K, Ross N, Meltzer S, et al. Gestational diabetes mellitus in mothers as a diabetes predictor in fathers: a retrospective cohort analysis. Diabetes Care. 2015;38(9):e130-e131.

29. Pace R, Brazeau AS, Meltzer S, Rahme E, Dasgupta K. Conjoint associations of gestational diabetes and hypertension with diabetes, hypertension, and cardiovascular disease in parents: a retrospective cohort study. Am J Epidemiol. 2017;186(10):1115-1124.

30. Pampalon R, Hamel D, Gamache P, Raymond G. A deprivation index for health planning in Canada. Chronic Dis Can. 2009;29(4):178-191.

31. Diabetes Canada Clinical Practice Guidelines Expert Committee, Feig DS, Berger H, et al. Diabetes and pregnancy. Can J Diabetes. 2018;42 (Suppl 1):S255-S282.

32. Alaghehbandan R, Macdonald D, Barrett B, Collins K, Chen Y. Using administrative databases in the surveillance of depressive disorders-case definitions. Popul Health Manag. 2012;15(6):372-380.

33. Rahme E, Low NC, Lamarre S, et al. Attempted suicide among students and young adults in Montreal, Quebec, Canada: a retrospective crosssectional study of hospitalized and nonhospitalized suicide attempts based on chart review. Prim Care Companion CNS Disord. 2015;17(5).
34. Kramer MS, Platt RW, Wen SW, et al. A new and improved populationbased Canadian reference for birth weight for gestational age. Pediatrics. 2001;108(2):e35.

35. Kisely S, Lin E, Gilbert C, Smith M, Campbell LA, Vasiliadis HM. Use of administrative data for the surveillance of mood and anxiety disorders. Aust N Z J Psychiatry. 2009;43(12):1118-1125.

36. Committee on Obstetric Practice. The American College of Obstetricians and Gynecologists Committee Opinion no. 630. Screening for perinatal depression. Obstet Gynecol. 2015;125(5):1268-1271.

37. Mautner E, Greimel E, Trutnovsky G, Daghofer F, Egger JW, Lang U. Quality of life outcomes in pregnancy and postpartum complicated by hypertensive disorders, gestational diabetes, and preterm birth. J Psychosom Obstet Gynaecol. 2009;30(4):231-237.

38. Katon JG, Russo J, Gavin AR, Melville JL, Katon WJ. Diabetes and depression in pregnancy: is there an association? J Womens Health. 2011;20(7):983-989.

39. Huang T, Rifas-Shiman SL, Ertel KA, et al. Pregnancy hyperglycaemia and risk of prenatal and postpartum depressive symptoms. Paediatr Perinat Epidemiol. 2015;29(4):281-289.

40. Mcgarry J, Kim H, Sheng X, Egger M, Baksh L. Postpartum depression and help-seeking behavior. J Midwifery Womens Health. 2009;54(1):50-56

41. da Costa D, Zelkowitz P, Nguyen TV, Deville-Stoetzel JB. Mental health help-seeking patterns and perceived barriers for care among nulliparous pregnant women. Arch Womens Ment Health. 2018;21(6):757-764.

42. Archambault C, Arel R, Filion KB. Gestational diabetes and risk of cardiovascular disease: a scoping review. Open Med. 2014;8(1):e1-e9.

43. Bellamy L, Casas JP, Hingorani AD, Williams D. Type 2 diabetes mellitus after gestational diabetes: a systematic review and meta-analysis. Lancet. 2009;373(9677):1773-1779.

44. Goodman JH. Influences of maternal postpartum depression on fathers and on father-infant interaction. Infant Ment Health J. 2008;29(6):624-643.

45. Paulson JF, Bazemore SD. Prenatal and postpartum depression in fathers and its association with maternal depression: a meta-analysis. JAMA. 2010;303(19):1961-1969.

46. Underwood L, Waldie KE, Peterson E, et al. Paternal depression symptoms during pregnancy and after childbirth among participants in the growing up in New Zealand study. JAMA Psychiatry. 2017;74(4):360-369.

47. Wee KY, Skouteris H, Pier C, Richardson B, Milgrom J. Correlates of ante- and postnatal depression in fathers: a systematic review. $J$ Affect Disord. 2011;130(3):358-377.

48. Paulson JF, Bazemore SD, Goodman JH, Leiferman JA. The course and interrelationship of maternal and paternal perinatal depression. Arch Womens Ment Health. 2016;19(4):655-663.

49. Xu F, Sullivan E, Binns C, Homer CS. Mental disorders in new parents before and after birth: a population-based cohort study. BJPsych Open. 2016;2(3):233-243.

50. Ramchandani PG, Stein A, O’Connor TG, Heron J, Murray L, Evans J. Depression in men in the postnatal period and later child psychopathology: a population cohort study. J Am Acad Child Adolesc Psychiatry. 2008;47(4):390-398.

51. Kvalevaag AL, Ramchandani PG, Hove O, et al. Does paternal mental health in pregnancy predict physically aggressive behavior in children? Eur Child Adolesc Psychiatry. 2014;23(10):993-1002.

52. Nath S, Psychogiou L, Kuyken W, Ford T, Ryan E, Russell G. The prevalence of depressive symptoms among fathers and associated risk factors during the first seven years of their child's life: findings from the Millennium Cohort Study. BMC Public Health. 2016;16:509. 


\section{Supplementary materials}

Table SI ICD, version 9 and 10 codes, used to identify cases of depression, self-harm, and suicide in administrative databases

\begin{tabular}{|c|c|}
\hline \multirow{2}{*}{\multicolumn{2}{|c|}{$\begin{array}{l}\text { ICD system } \text { Codes } \\
\text { Depression }\end{array}$}} \\
\hline & \\
\hline \multicolumn{2}{|r|}{ 296.20, 296.2І, 296.22, 296.23, 296.3, 296.3І, 296.32, 296.33, 296.34, 296.99, 30І.І, 309.0, 3ІІ, 3ІІ .0, 648.40, 648.42, 648.44} \\
\hline ICD-I0 & $\begin{array}{l}F 32.0, F 32 . I, F 32.2, F 32.3, F 32.4, F 32.8 \text {, F32.9, F33.0, F33.I, F33.2, F33.3, F33.4, F33.8, F33.9, F34.0, F34.I, F34.8, F34.9, F38.0, F38.I, } \\
F 38.8, F 39, F 53.0, F 53 . I, F 53.8, F 53.9\end{array}$ \\
\hline \multicolumn{2}{|c|}{ Self-harm/suicide } \\
\hline ICD-9 & E85.x, E86.2, E86.8, E95.x \\
\hline ICD-10 & $\mathrm{X} 6 \mathrm{x}, \mathrm{X7x}, \mathrm{X80}, \mathrm{X81}, \mathrm{X82}, \mathrm{X83}, \mathrm{X84}$ \\
\hline
\end{tabular}

Table S2 Using one outpatient or one inpatient code for depression, depression incident proportions, incidence rates per I,000 person-years, and adjusted and unadjusted HRs in mothers and fathers in relationship with GDM status, as computed through stratified Cox proportional regression hazards models (Quebec, Canada; 1990-2007)

\begin{tabular}{|c|c|c|c|c|c|c|}
\hline & \multicolumn{2}{|c|}{24 weeks gestation to delivery } & \multicolumn{2}{|c|}{$\begin{array}{l}\text { Delivery to I year } \\
\text { postpartum }\end{array}$} & \multicolumn{2}{|c|}{ I year postpartum to study end } \\
\hline & $\begin{array}{l}\text { Non-GDM } \\
\text { pregnancy }\end{array}$ & $\begin{array}{l}\text { GDM } \\
\text { pregnancy }\end{array}$ & $\begin{array}{l}\text { Non-GDM } \\
\text { pregnancy }\end{array}$ & $\begin{array}{l}\text { GDM } \\
\text { pregnancy }\end{array}$ & $\begin{array}{l}\text { Non-GDM } \\
\text { pregnancy }\end{array}$ & $\begin{array}{l}\text { GDM } \\
\text { pregnancy }\end{array}$ \\
\hline \multicolumn{7}{|l|}{ Mothers } \\
\hline Cases of depression $(n)$ & $\begin{array}{l}0.42 \% \\
(124)\end{array}$ & $\begin{array}{l}0.78 \% \\
(228)\end{array}$ & $\begin{array}{l}1.72 \% \\
(503)\end{array}$ & $\begin{array}{l}1.70 \% \\
(496)\end{array}$ & $\begin{array}{l}20.78 \% \\
(6,067)\end{array}$ & $\begin{array}{l}21.88 \% \\
(6,389)\end{array}$ \\
\hline $\begin{array}{l}\text { Depression cases/I,000 } \\
\text { person-years }(95 \% \mathrm{Cl})\end{array}$ & $\begin{array}{l}12.73 \\
(10.68,15.06)\end{array}$ & $\begin{array}{l}23.44 \\
(20.59,26.58)\end{array}$ & $\begin{array}{l}13.42 \\
(12.29, \mid 4.62)\end{array}$ & $\begin{array}{l}13.52 \\
(12.39,14.72)\end{array}$ & $\begin{array}{l}18.65 \\
(18.18,19.11)\end{array}$ & $\begin{array}{l}19.78 \\
(19.29,20,26)\end{array}$ \\
\hline Unadjusted HR $(95 \% \mathrm{Cl})$ & $\begin{array}{l}\text { I } \\
\text { (reference) }\end{array}$ & $\begin{array}{l}1.28 \\
(0.95,1.73)\end{array}$ & $\begin{array}{l}\text { I } \\
\text { (reference) }\end{array}$ & $\begin{array}{l}0.98 \\
(0.87, \mathrm{I} . \mathrm{II})\end{array}$ & $\begin{array}{l}\text { I } \\
\text { (reference) }\end{array}$ & $\begin{array}{l}1.05 \\
(1.01,1.09)\end{array}$ \\
\hline Adjusted $\mathrm{HR}^{\mathrm{a}}(95 \% \mathrm{Cl})$ & I & $\begin{array}{l}1.44 \\
(0.89,2.35)\end{array}$ & I & $\begin{array}{l}0.91 \\
(0.80,1.47)\end{array}$ & $\begin{array}{l}\text { I } \\
\text { (reference) }\end{array}$ & $\begin{array}{l}1.08 \\
(0.98,1.19)\end{array}$ \\
\hline \multicolumn{7}{|l|}{ Fathers } \\
\hline Cases of depression $(n)$ & $\begin{array}{l}0.10 \% \\
(31)\end{array}$ & $\begin{array}{l}0.12 \% \\
(38)\end{array}$ & $\begin{array}{l}0.72 \% \\
(229)\end{array}$ & $\begin{array}{l}0.72 \% \\
(228)\end{array}$ & $\begin{array}{l}11.90 \% \\
(3,770)\end{array}$ & $\begin{array}{l}11.96 \% \\
(3,790)\end{array}$ \\
\hline $\begin{array}{l}\text { Depression cases/I,000 } \\
\text { person-years }(95 \% \mathrm{Cl})\end{array}$ & $\begin{array}{l}3.19 \\
(2.25,4.4 I)\end{array}$ & $\begin{array}{l}3.91 \\
(2.86,5.25)\end{array}$ & $\begin{array}{l}5.63 \\
(4.95,6.39)\end{array}$ & $\begin{array}{l}5.65 \\
(4.96,6.4 I)\end{array}$ & $\begin{array}{l}10.43 \\
(10.10,10.76)\end{array}$ & $\begin{array}{l}10.49 \\
(10.16,10.83)\end{array}$ \\
\hline Unadjusted HR $(95 \% \mathrm{Cl})$ & I & $\begin{array}{l}1.14 \\
(0.64,2.05)\end{array}$ & I & $\begin{array}{l}1.00 \\
(0.83,1.20)\end{array}$ & $\begin{array}{l}\text { I } \\
\text { (reference) }\end{array}$ & $\begin{array}{l}1.01 \\
(0.96,1.06)\end{array}$ \\
\hline Adjusted $\mathrm{HR}^{\mathrm{a}}(95 \% \mathrm{Cl})$ & (reference) & $\begin{array}{l}2.0 \mathrm{I} \\
(0, \mathrm{INF})\end{array}$ & (reference) & $\begin{array}{l}0.92 \\
(0.55,1.38)\end{array}$ & $\begin{array}{l}\text { I } \\
\text { (reference) }\end{array}$ & $\begin{array}{l}1.00 \\
(0.95,1.05)\end{array}$ \\
\hline
\end{tabular}

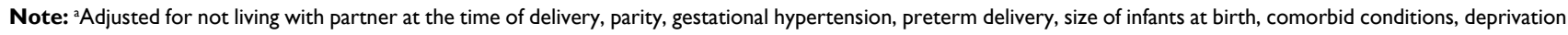
level, and ethnocultural background.

Abbreviations: GDM, gestational diabetes mellitus; INF, infinity.

Clinical Epidemiology

\section{Publish your work in this journal}

Clinical Epidemiology is an international, peer-reviewed, open access, online journal focusing on disease and drug epidemiology, identification of risk factors and screening procedures to develop optimal preventative initiatives and programs. Specific topics include: diagnosis, prognosis, treatment, screening, prevention, risk factor modification,
Dovepress

systematic reviews, risk and safety of medical interventions, epidemiology and biostatistical methods, and evaluation of guidelines, translational medicine, health policies and economic evaluations. The manuscript management system is completely online and includes a very quick and fair peer-review system, which is all easy to use. 